\title{
Chamomile Floricolous Downy Mildew Caused by Peronospora radii
}

\author{
Bojan Duduk, ${ }^{1, \dagger}$ Nataša Duduk, ${ }^{2}$ Ivana Vico, ${ }^{2}$ Jelena Stepanović, ${ }^{1}$ Tatjana Marković, ${ }^{3}$ \\ Emil Rekanović, ${ }^{1}$ Michael Kube, ${ }^{4}$ and Dragoja Radanović ${ }^{3}$
}

\author{
${ }^{1}$ Institute of Pesticides and Environmental Protection, Belgrade, Serbia \\ ${ }^{2}$ University of Belgrade, Faculty of Agriculture, Belgrade, Serbia \\ ${ }^{3}$ Institute for Medicinal Plant Research "Dr Josif Pančić", Belgrade, Serbia \\ ${ }^{4}$ University of Hohenheim, Integrative Infection Biology Crops-Livestock, Stuttgart, Germany \\ Accepted for publication 29 July 2019.
}

\begin{abstract}
Floricolous downy mildews (Peronospora, oomycetes) are a small, monophyletic group of mostly inconspicuous plant pathogens that induce symptoms exclusively on flowers. Characterization of this group of pathogens, and information about their biology, is particularly sparse. The recurrent presence of a disease causing flower malformation which, in turn, leads to high production losses of the medicinal herb Matricaria chamomilla in Serbia has enabled continuous experiments focusing on the pathogen and its biology. Peronospora radii was identified as the causal agent of the disease, and morphologically and molecularly characterized. Diseased chamomile flowers showed severe malformations of the disc and ray florets, including phyllody and secondary inflorescence formation, followed
\end{abstract}

ABSTRACT by the onset of downy mildew. Phylogeny, based on internal transcribed spacer and $\cos 2$, indicates clustering of the Serbian $P$. radii with other $P$. radii from chamomile although, in $\operatorname{cox} 2$ analyses, they formed a separate subcluster. Evidence pointing to systemic infection was provided through histological and molecular analyses, with related experiments validating the impact of soilborne and blossom infections. This study provides new findings in the biology of $P$. radii on chamomile, thus enabling the reconstruction of this floricolous Peronospora species' life cycle.

Keywords: ecology and epidemiology, life cycle, Matricaria chamomilla, systemic infection
The genus Peronospora (family Peronosporaceae), which contains approximately 400 species, is the most species-rich among oomycetes (Constantinescu 1991) and includes highly adapted biotrophs that cause downy mildews (Thines and Kamoun 2010; Voglmayr 2003); however, the fact that they cannot be cultured in vitro has hampered characterization of these biologically interesting plant pathogens. Most downy mildews induce symptoms systemically or predominantly on the leaves and stem of their hosts (foliicolous), while a small group (floricolous) is mostly inconspicuous and induces symptoms exclusively on flowers (Thines and Kummer 2013). Floricolous downy mildews include Peronospora violacea, P. stigmaticola, P. jagei, $P$. corollae, $P$. tranzscheliana, and $P$. radii. Most of the reports of floricolous downy mildews in the past were based on symptoms observed on flowers as well as sporulation and molecular features (Horáková and Skalický 1989; Thines and Kummer 2013; Voglmayr 2003). Information about the development of these biotrophic pathogens in their hosts is particularly limited, although there has been an indication that $P$. violacea, a floricolous downy mildew, may be systemic (Horáková and Skalický 1989). Additionally, information about the life cycle (biology) of floricolous downy mildews is particularly sparse. Among floricolous downy mildews, $P$. radii is a remarkable exception, because it apparently behaves in a floricolous way on chamomile (Matricaria chamomilla), whereas it is foliicolous on chrysanthemum (Chrysanthemum spp. and Argyranthemum frutescens) (Ben-ze'ev et al. 1987; Constantinescu 1989; Koike et al. 2004). This led Horáková and Skalický (1989) to define it as a facultative floricolous parasite.

${ }^{\dagger}$ Corresponding author: B. Duduk; bojan.duduk@pesting.org.rs

Funding: Ministarstvo Prosvete, Nauke i Tehnološkog Razvoja [Ministry of Education and Science], Republic of Serbia, grant numbers TR31043 and TR31072.

The author(s) declare no conflict of interest.

(C) 2019 The American Phytopathological Society
Phylogenetic analyses have shown that floricolous Peronospora spp., including $P$. radii, form a strongly supported monophyletic clade in the genus Peronospora (Thines and Kummer 2013; Voglmayr 2003). Nonetheless, phylogenetic studies of $P$. radii from chrysanthemum have not been performed despite the different hosts and symptoms.

$P$. radii infection has been detected in Italian chamomile production fields but not as a serious threat to commercial interests (Buonaurio et al. 2004). Furthermore, despite reports of economic losses caused by $P$. radii related to cultivated Chrysanthemum spp. and A. frutescens (Ben-ze'ev et al. 1987; Constantinescu 1989; Koike et al. 2004), it has not been considered a major threat to chrysanthemum plant production (Thines and Choi 2016). Serbia is one of the main European producers of chamomile (Matricaria chamomilla) and, in the Banat region, this important item in herbal medicine has been a traditional crop for more than 40 years. In the restricted area of Pančevo (Banat region, northern Serbia), deformed flowerheads with downy mildew first appeared in 2004 and, since then, the disease has become a devastating obstacle to maintaining viable chamomile production in the area.

The economic importance, persistence, and high incidence of downy mildew on chamomile in Serbia initiated and enabled this study. Following identification of $P$. radii as the causal agent of the disease, a series of experiments focusing on the biology of $P$. radii on chamomile was performed. Hence, the objectives of this study were to (i) morphologically and phylogenetically characterize $P$. radii in Serbia, (ii) confirm the systemic presence of $P$. radii in chamomile plants, and (iii) elucidate the life cycle of the pathogen on chamomile.

\section{MATERIALS AND METHODS}

Symptom observation and sample collection. All symptomatic and asymptomatic plants, as well as soil samples, were collected from an $M$. chamomilla production field where downy mildew was present. The area of the field, located in Pančevo, 
northern Serbia (Banat region), was 1 ha. Chamomile has been grown in a monoculture in this field since 2010, with the occurrence and development of the disease monitored in 2015, 2016, and 2017. Field observations included monitoring flower deformation and pathogen sporulation over 2-week intervals, starting from 1 April and running until 1 June (1 April, 15 April, 1 May, 15 May, and 1 June, within a 2 day window). On each occasion when the symptoms were observed, 20 symptomatic and 5 asymptomatic plants from the immediate proximity were collected by cutting them near the soil surface. All collected plants were examined microscopically, and disease incidence was calculated by counting on 15 May for each year based on the percentage of diseased plants in 10 randomly distributed areas (each $0.25 \mathrm{~m}^{2}$ ) in the field.

The presence of the disease was also monitored during the vegetation period on volunteer $M$. chamomilla surrounding the field and Tripleurospermum perforatum (scentless chamomile) sparsely present in the field as weeds. One $T$. perforatum plant showing flower deformations was found and collected on 1 June 2017 for microscopic and molecular analysis.

For etiological investigation (pathogen identification based on morphological and molecular analysis), 10 selected symptomatic and 5 asymptomatic plants collected on 15 May 2015 were used. To determine whether the pathogen was systemically present in plants (histopathological, ultrastructural, and molecular analyses), four symptomatic and two asymptomatic plants were selected from those collected on 15 May 2016. Samples collected on 1 June 2017 served as a conidia source for germination tests.

Five overwintered, young, asymptomatic chamomile plants (at the beginning of stem elongation, approximately a month before inflorescence, BBCH 30, according to Hess et al. [1997]) were collected in March 2017 in order to estimate infection time under natural conditions (molecular analysis).

In order to determine whether the soil was the source of inoculum, soil samples for growth chamber experiments were collected in 2015 and 2016 (25 August), while pathogen presence and identity in plants grown from infested soil were checked via symptom observation as well as microscopic and molecular analysis.

Observation of reproductive structures and conidial germination. Inflorescence samples were examined via light microscopy (LM) as either intact dry plant parts or wet mounts, the latter of which were prepared by dipping either intact or crushed plant parts into a water droplet on a microscope slide. The presence of sporulation on the plant surface was examined by transferring structures from the plant surface to the water drops, using a sterile microscopic needle. The morphology of conidiophores (appearance, total length, trunk length and width, presence and width of base swelling, number and size of branchlets, and branching pattern), conidia, and oospores (color, shape, and size) were then determined from 10 collected symptomatic plants (five flower heads per plant were selected and, from each, three ligulate flowerets were used for slide preparation; 15 slides per sample were examined, 150 in total).

Conidial germination and appressoria formation were examined on naturally infected plants after incubation for $24 \mathrm{~h}$ in moist conditions (in plastic bags) at $15^{\circ} \mathrm{C}$ in the dark. After incubation, the ligulate florets were torn off, placed in water droplets on microscope slides, and then examined via LM. One flower head per sample was examined.

Effect of the host on conidial germination and appressoria formation. The effect of the presence and absence of ligulate chamomile florets on conidial germination and appressoria formation was assessed in the following experiments: (i) a healthy chamomile ligulate floret was placed in $100 \mu \mathrm{l}$ of sterile water on a microscopic slide next to a ligulate floret of M. chamomilla or T. perforatum with downy mildew, (ii) a healthy ligulate floret of $M$. chamomilla was placed on a microscopic slide and covered with $100 \mu \mathrm{l}$ of conidial suspension $\left(10^{6}\right.$ conidia/ml $)$ obtained from naturally infected $M$. chamomilla flowers, and (iii) a 100- $\mu$ l conidial suspension $\left(10^{6}\right.$ conidia $\left./ \mathrm{ml}\right)$ was placed on a microscopic slide without the presence of the host. Five slides per test were placed onto Petri plates on moist paper towels and kept at $15^{\circ} \mathrm{C}$ in the dark. After $24 \mathrm{~h}$, conidial germination and appressoria formation were observed. Each experiment was repeated twice. Infected and healthy plants for these experiments were collected on 1 June 2017.

Molecular detection and phylogenetic analyses. Amplification and sequence analyses of the internal transcribed spacer (ITS) region were used to identify and characterize $P$. radii in order to confirm pathogen presence in flowers, different stem parts, and plants from histological and ultrastructural analyses as well as those grown in growth chamber experiments. In total, 150 samples underwent molecular detection. For identification of the pathogen, nucleic acid extraction and the ITS region amplification were performed on chamomile flowers of 10 symptomatic and 5 asymptomatic plants collected in May 2015. ITS region amplification was performed separately for flowers and different stem parts (from below the flowers and above the root neck) on the following samples: 4 symptomatic and 2 asymptomatic plants selected for the histological and ultrastructural analysis, 120 (60 symptomatic and 60 asymptomatic) plants from infested soil experiment, 3 asymptomatic plants with oospores, and 1 T. perforatum plant (130 plants in total). For the five young asymptomatic chamomile plants, extraction was performed from an available stem (approximately $4 \mathrm{~cm}$ in length). Total nucleic acids were extracted by following the cetyltrimethylammonium bromide protocol (Doyle and Doyle 1990), before being precipitated with isopropanol, resuspended in a Tris-EDTA buffer (10 $\mathrm{mM}$ Tris [pH 8] and $1 \mathrm{mM}$ EDTA), and stored at $-20^{\circ} \mathrm{C}$. The oomycete-specific primer DC6 (Bonants et al. 1997), in combination with the universal primer ITS4 (White et al. 1990), was applied in order to amplify the ITS region. The PCR $(25 \mu \mathrm{l})$ contained $20 \mathrm{ng}$ of template DNA, 1× PCR MasterMix (Thermo Fisher Scientific, Vilnius, Lithuania) and $0.4 \mu \mathrm{M}$ each primer. Amplification parameters were chosen as described previously (Silvar et al. 2005).

Additionally, in 13 selected samples (4 samples/year from $M$. chamomilla and 1 from $T$. perforatum), oomycete cox 2 gene amplification was performed using a cox $2 \mathrm{f} / \mathrm{r}$ primer pair with amplification parameters described previously (Hudspeth et al. 2000) and the PCR mix as described above. In view of the fact that phyllody and other symptoms characteristic of phytoplasma infection were observed on chamomile plants, phytoplasma presence was assessed by using phytoplasma $16 \mathrm{~S}$ ribosomal DNAspecific primers in nested PCR, with amplification parameters and the PCR mix as described previously (Duduk et al. 2013). Samples lacking DNA were employed as negative controls for all reactions, while PCR products $(6 \mu \mathrm{l})$ were observed in $1 \%$ agarose gel, stained in ethidium bromide, and visualized with a UV transilluminator.

The DC6/ITS4 and cox $2 \mathrm{f} / \mathrm{r}$ PCR products ( $3^{\prime}$ portion of $18 \mathrm{~S}$ ribosomal RNA, complete sequences of intergenic spacer 1, 5.8S ribosomal RNA intergenic spacer 2 , and $5^{\prime}$ portions of $28 \mathrm{~S}$ ribosomal RNA and the oomycetes mitochondrially encoded cytochrome c oxidase subunit II gene $\operatorname{cox} 2$, respectively) for selected samples were sequenced in both directions, with primers applied for amplification (Macrogen Inc., Seoul, Korea). For sequencing of ITS, $34 M$. chamomilla plants were selected. The cox 2 gene was sequenced additionally for 12 of those 34 . For the $T$. perforatum sample, sequencing of both loci was performed. The obtained sequences were assembled using Pregap4 from the Staden program package (Staden et al. 2000) and then deposited in GenBank. A 1,171-nucleotide (nt)-long nucleotide sequence of ITS and a 581ntlong partial sequence of cox 2 of $P$. radii strain 44/15 from chamomile were deposited in GenBank under accession numbers MF319537 and MF346345, respectively. All aligned matrices are deposited in Treebase (accession S24700).

The obtained sequences were compared with those publicly available from NCBI's GenBank database, by applying the 
MegaBLAST algorithm, and they were then aligned with those of strains representing the closest species using ClustalX (Thompson et al. 1997), under MEGA version 7 (Kumar et al. 2016). Evolutionary history was inferred based on the ITS and cox2 sequences of two selected $P$. radii strains (44/15 and 101/17 from $M$. chamomilla and $T$. perforatum, respectively) from this study, seven other $P$. radii strains, and a number of representatives of the genus Peronospora, using the maximum-parsimony (MP) and maximum-likelihood (ML) methods (MEGA 7). MP trees were obtained by applying the Close-Neighbor-Interchange algorithm at search level 5, with initial trees obtained through the random addition of sequences ( 10 replicates). For ML, a sequence evolution model was first chosen using the "find best model" option in MEGA7. Initial trees for the heuristic search were obtained automatically by applying the Neighbor-Join and BioNJ algorithms. To estimate the statistical significance of the inferred clades, 1,000 bootstraps were performed.

Histological and ultrastructural analysis. In order to confirm the systemic nature of infection, the presence of pathogen structures in different parts of the stem was assessed. Four symptomatic plants with sporulation, where the presence of $P$. radii was confirmed molecularly in flowers and stems, were selected for histological and ultrastructural stem analysis. From these and two noninfected plants as negative controls, six stem sections per plant (three sections from the stem below the flowers and three from the stem above the root neck) were analyzed separately.

The samples were fixed in $3.5 \%$ glutaraldehyde in a $0.1-\mathrm{M}$ phosphate buffer, postfixed in $1 \%$ osmium tetroxide in the same buffer for $2 \mathrm{~h}$ at 4 to $8^{\circ} \mathrm{C}$, and then routinely dehydrated using increasing concentrations of ethanol, before being embedded in Araldite (Fluka, Seelze, Germany). All sections were obtained on a Leica UC6 ultramicrotome (Leica Microsystems, Wetzlar, Germany) using glass or diamond knives. Tissue sections $1 \mu \mathrm{m}$ in thickness were mounted on glass microscope slides, stained with $1 \%$ toluidine blue in $1 \%$ borax, and examined under a light microscope. Samples in which hyphae-like structures were observed were subjected to transmission electron microscopy (TEM), for which ultrathin sections (90 to $100 \mathrm{~nm}$ ) were obtained using a diamond knife (Diatome, Biel, Switzerland), then stained with uranyl acetate/lead citrate using Leica EM STAIN (Leica Microsystems). The sections were examined on a CM 12 transmission electron microscope (Philips/FEI, Eindhoven, The Netherlands), operated at $60 \mathrm{kV}$ and equipped with an SIS MegaView III digital camera (Olympus Soft Imaging Solutions, Münster, Germany). The whole procedure was performed at the Center for Electron Microscopy (University of Belgrade, Faculty of Biology, Belgrade, Serbia).

Impact of the infested soil on disease development. To determine the source of inoculum and to maintain the pathogen, five samples of the surface layer of soil (11.25 liters), without visible plant debris, were collected each year (10 soil samples in total) from areas randomly distributed in the experimental field, then transferred to pots ( 50 by 15 by $15 \mathrm{~cm}$, length by width by depth) and used for two experiments. In both instances, pots with soil samples were kept in a growth chamber at 15 to $18^{\circ} \mathrm{C}$ and 60 to $70 \%$ relative humidity under a photoperiod of $16 \mathrm{~h}$ of light and $8 \mathrm{~h}$ of darkness, thus ensuring the absence of any airborne inoculum. In the first experiment, chamomile plants grew spontaneously from seed naturally present in the collected soil samples. The presence of disease symptoms and pathogen sporulation on the plants was checked continuously for 6 months (until 1 month after flowering), following which all 151 plants were removed and examined microscopically. For the second experiment, after removing the plants, the pots with plant-free soil samples were kept for an additional 2 months to check for further chamomile germination. Because chamomile seed were exhausted from the soil (no further germination occurred), commercially available seed (Semesemena,
Belgrade, Serbia) was sown at approximately $0.1 \mathrm{~g} /$ pot. As a negative control, commercially available seed were sown in commercial potting substrate. The presence of disease was checked on all 154 newly sprouted plants, as described above. Three symptomatic and three asymptomatic plants per pot, from each experiment, were subjected to molecular detection to confirm infection.

\section{RESULTS}

Chamomile disease symptoms. Diseased chamomile plants flowered with malformed flower heads approximately a week earlier than the healthy ones, which was the first sign that the disease was present. This was recorded on 15 April 2016 and 1 May 2015 and 2017, when only malformed flowers, uniformly distributed across the field, were present. On later observation dates, both healthy and diseased flowers were recorded. Flower heads on the diseased plants were disproportionate in terms of the sizes and numbers of disks and ray florets, and various malformations also occurred (Fig. 1). Symptoms ranged from mild deformation to the absence of disc florets. Malformed ray florets were larger, more numerous, bent, and curved, while disk florets were of abnormal shape and size, from enlarged to unnoticeable, and deformed (Fig. $1 \mathrm{~A}$ and $\mathrm{B})$. In some cases, primary inflorescence was replaced by indeterminate shoots with leaf-like organs (phyllody) and degenerated secondary inflorescences (Fig. 1C and D). Some flower heads exhibited symptoms on one of the floret types, while others displayed changes on both. At the beginning of the blooming period (1 May), symptomatic flowers prevailed, while down formation was absent on the surface. Later in the season (15 May), on the symptomatic plants, downy mildew was found scattered on inflorescence, which then became densely agglomerated toward the end of the season and completely covered the ligulate florets (Fig. 1A, C, and E). Symptoms and signs were observed only on the flower heads, whereas the stem and leaves remained without any visual sign of pathogen presence. The same symptoms and disease development were observed on some of the volunteer M. chamomilla.

Chamomile plants with abnormal, hampered, or absent flower development and downy mildew could not be harvested, or their flowers used. The incidences of the disease in the experimental field in 2015, 2016, and 2017 were 75.23, 76.13, and 52.1\%, respectively.

Pathogen morphology. In symptomatic $M$. chamomilla plants, $P$. radii was detected via microscopy, and its presence was confirmed by molecular detection (see below). Microscopic observations showed the presence of hyaline conidiophores, which branched mainly dichotomously, four to five times (Fig. 2A and B). Conidiophores were erect $(277.4$ to $413.87 \mu \mathrm{m})$, and the trunk (143 to 270.68 by 7.87 to $17.37 \mu \mathrm{m})$ had a swollen base (22.79 to $26.9 \mu \mathrm{m})$. Branches ended in two to very occasionally three cylindrical ultimate branchlets. The terminal branchlet was 5.03 to $21.74 \mu \mathrm{m}$ and the lateral branchlet 3.66 to $10.66 \mu \mathrm{m}$ long. Conidia were brownish, obovoidal to broadly ellipsoidal or globose, with apapillate apices (18 to) 23.52 to 28.48 (to 34.3 ) $\mu \mathrm{m}$ long, (13.9 to) 16.7 to 19.5 (to 26.9$) \mu \mathrm{m}$ wide, means ( \pm standard deviation) of $26.13 \pm 3.45$ by $18.21 \pm 2.32 \mu \mathrm{m}$, a length-to-width ratio of ( 1 to) 1.3 to 1.6 (to 2.03), and an average of $1.44 \pm 0.2 \mu \mathrm{m}(n=100)$ (Fig. 2C). Oospores were observed regularly in the ligulate floret tissue of symptomatic plants collected during May (Fig. 2D). Oogonia were yellowish and globose, and they measured (38.11 to) 42.52 to 48.98 (to 51.94$) \mu \mathrm{m}$, mean $45.54 \pm 3.74 \mu \mathrm{m}$, with walls 0.65 to $2.3 \mu \mathrm{m}$ thick $(n=72)$. Oospores were aplerotic, yellowish, and globose, and they measured (21.66 to) 25.42 to 31.62 (to 35.51 ) $\mu$ m, mean $28.3 \pm$ $3.63 \mu \mathrm{m}$, with a wall 1.09 to $3.62 \mu \mathrm{m}$ thick $(n=72)$. Oospores were also observed in ligulate flowers of asymptomatic plants collected from the immediate proximity of other plants showing symptoms and covered with down. The oospores were recorded in one of five 
examined plants collected on 1 June 2016 and 15 May and 1 June 2017.

Conidial germination and appressoria formation. After $24 \mathrm{~h}$ of incubation of naturally infected chamomile plants under moist conditions at $15^{\circ} \mathrm{C}$ in the dark, conidia germinated on ligulate florets, forming a single germ tube arising from the side of each conidium (Fig. 2E). The germ tube ended with a subglobose appressorium, which measured $14.41 \pm 1.41$ by $11.9 \pm 1.76 \mu \mathrm{m}(n=$ 12) (Fig. 2F).

It was observed that, when ligulate florets of healthy M. chamomilla were placed on microscopic slides next to naturally infected M. chamomilla or T. perforatum ligulate florets, conidia germinated and, then, germ tubes elongated toward the healthy ligulate florets and formed appressoria (Fig. 2G). Similarly, when healthy $M$. chamomilla ligulate florets were placed into conidial suspension, conidial germination and appressoria formation occurred. However, when the conidia were placed in water drops, without the presence of healthy or infected host ligulate florets, they did germinate but the formation of appressoria was not observed.

$P$. radii causes systemic infection in chamomile. The examination of M. chamomilla stem sections via LM (Fig. 3) and TEM (Figs. 4 and 5) revealed hyphae-like structures in all infected plants, whereas such structures were not observed in noninfected plants. Pathogen hyphae were present in both parts of the stem-namely, the upper (below the inflorescence) and the lower (above the root neck) samples-and were localized in the intercellular xylem space, usually near the live parenchyma cells of xylem rays (Figs. 3 and 4). The LM and TEM observations of the cuttings showed that intercellular hyphae of $P$. radii were present in the xylem of all tested stem parts. Pathogen hyphae were observed among mature xylem tracheid cells but they were located more frequently close to young vital xylem cells or xylem parenchyma carrying the haustoria-like pathogen structures (Fig. 5). Wellstructured haustoria were also observed in the neighboring live parenchyma cells. The TEM observations revealed no phytoplasmalike structures in the analyzed samples.

Molecular detection confirms $P$. radii assignment and systemic infection. In accordance with the results presented above, PCR products (using the oomycete-specific primer DC6 and universal primer ITS4) of expected size (approximately $1.3 \mathrm{kbp}$ ) were obtained from the flowers (10 samples) and all tested parts (i.e., flowers, different stem parts from below the flowers and above the root neck from 64 samples) of all symptomatic $M$. chamomilla plants and one $T$. perforatum plant collected from the field. In the three asymptomatic specimens in which oospores were found, amplification was obtained from flowers but not from stem parts. Furthermore, amplification was noted in two of five young overwintering asymptomatic chamomile plants collected in March.
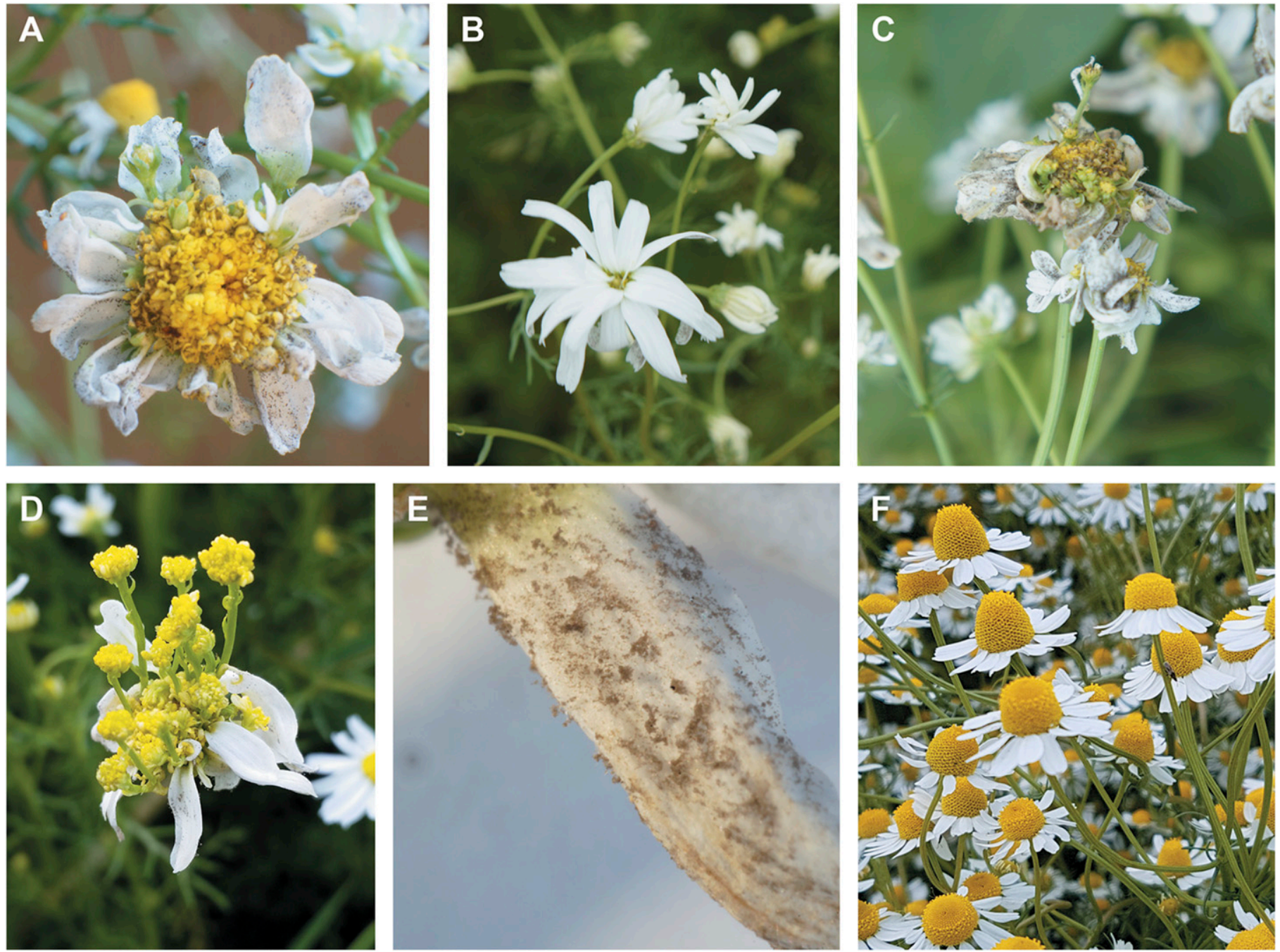

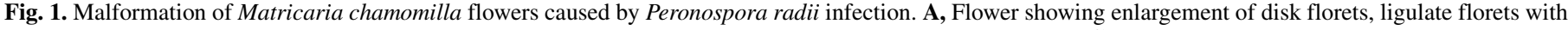

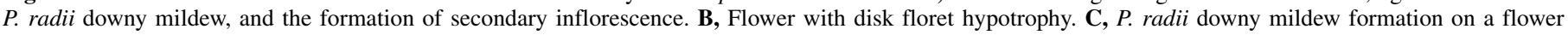

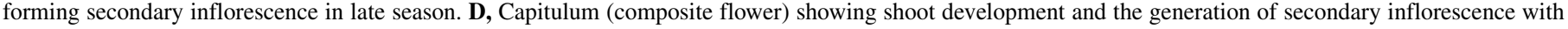
partially developed bracts. E, Ligulate floret covered with $P$. radii downy mildew (conidiophores and conidia). F, Healthy flowers. 
No amplification was obtained for the negative controls. Multiple sequence alignment of the determined sequences showed that ITS sequences for all $P$. radii collected from Serbia, from the 34 plants tested, were identical, and by far the highest similarity was observed with other sequences of $P$. radii deposited in NCBI GenBank (i.e., AY198296, JQ031182, JQ031183, JQ031180, and JQ031181 showing $1,1,3,3$, and 4 nt differences, respectively). With the cox $2 \mathrm{f} / \mathrm{r}$ primer pair, expected amplicons of approximately $600 \mathrm{bp}$ in length were obtained for selected symptomatic chamomile plants that were positive with DC6 and ITS4 primers. Determined cox 2 sequences of the $13 P$. radii collected from Serbia were identical, with the highest similarity observed with other $P$. radii $\operatorname{cox} 2$ sequences (e.g., KJ654262), showing 8 nt differences. No phytoplasma was detected in any of the examined chamomile plants.

Phylogenetic analyses of the amplified ITS region and cox2 sequences of the Serbian strains, aligned with the $P$. radii sequences and other floricolous and closely related publicly available nonfloricolous Peronospora spp., using the MP algorithm, resulted in the 10 most parsimonious phylogenetic trees in both analyses (data not shown). For each region, the most parsimonious phylogenetic trees had similar topologies. One of the equally parsimonious trees for each region is shown in Figure 6. In the ITS phylogenetic tree, the Serbian $P$. radii strains clustered within the highly supported $P$. radii clade, thereby confirming identification of the pathogen in the Serbian chamomile as $P$. radii. The cox 2 phylogenetic tree indicated the highly supported clustering of the two Serbian $P$. radii strains together with other $P$. radii strains from chamomile, although they formed a separate subcluster.

Soilborne infection of chamomile. Hundreds of chamomile seedlings germinated in soil samples in both growth chamber experiments (from seed naturally present and sown in). Of the large number of germinated seedlings, in both experiments, only 14 to 18 chamomile plants per pot reached inflorescence. There was no statistical difference in disease incidence for either experiment for the years compared; therefore, the results were pooled. In the first experiment, from a total of 151 flowering plants developed from naturally present seed, symptoms were observed on $69.54 \%$ while, in the second experiment, from a total of 154 plants from sown-in commercial seed, disease symptoms were noted on $68.83 \%$ of the plants. However, no sporulation was observed on any of the symptomatic plants in the growth chamber. Molecular detection with the specific PCR primers yielded amplicons of expected size from all tested symptomatic plants (60 in total), while symptomless plants remained negative. As a representative example, ITS amplicons from 1 chamomile plant/pot, totaling 20, were sequenced, and these sequences were identical with other $P$. radii collected from Serbia. Commercially available seed sown in noninfested soil showed no symptoms and yielded no amplicons when subjected to molecular analysis with the oomycete-specific primers.

\section{DISCUSSION}

In the present study, $P$. radii was identified as the causal agent of an economically important downy mildew on chamomile in the Pančevo region, Serbia, which has become the major limiting factor for production in the last several years. The pathogen was identified based on morphological and molecular features and, to the best of our knowledge, this is the first report of the presence of $P$. radii in Serbia. Examination of symptomatic flowers by LM revealed the presence of hyaline conidiophores, conidia, oogonia, and oospores, consistent with previous reports for $P$. radii, including its already described variability (Ben-ze'ev et al. 1987; Constantinescu 1989; Koike et al. 2004; Safránková and Müller 2007). Among typical obovoidal to broadly ellipsoidal conidia, we observed globose conidia less frequently, which reflected on the length/width ratio. $P$. radii conidia on chamomile were slightly smaller than those
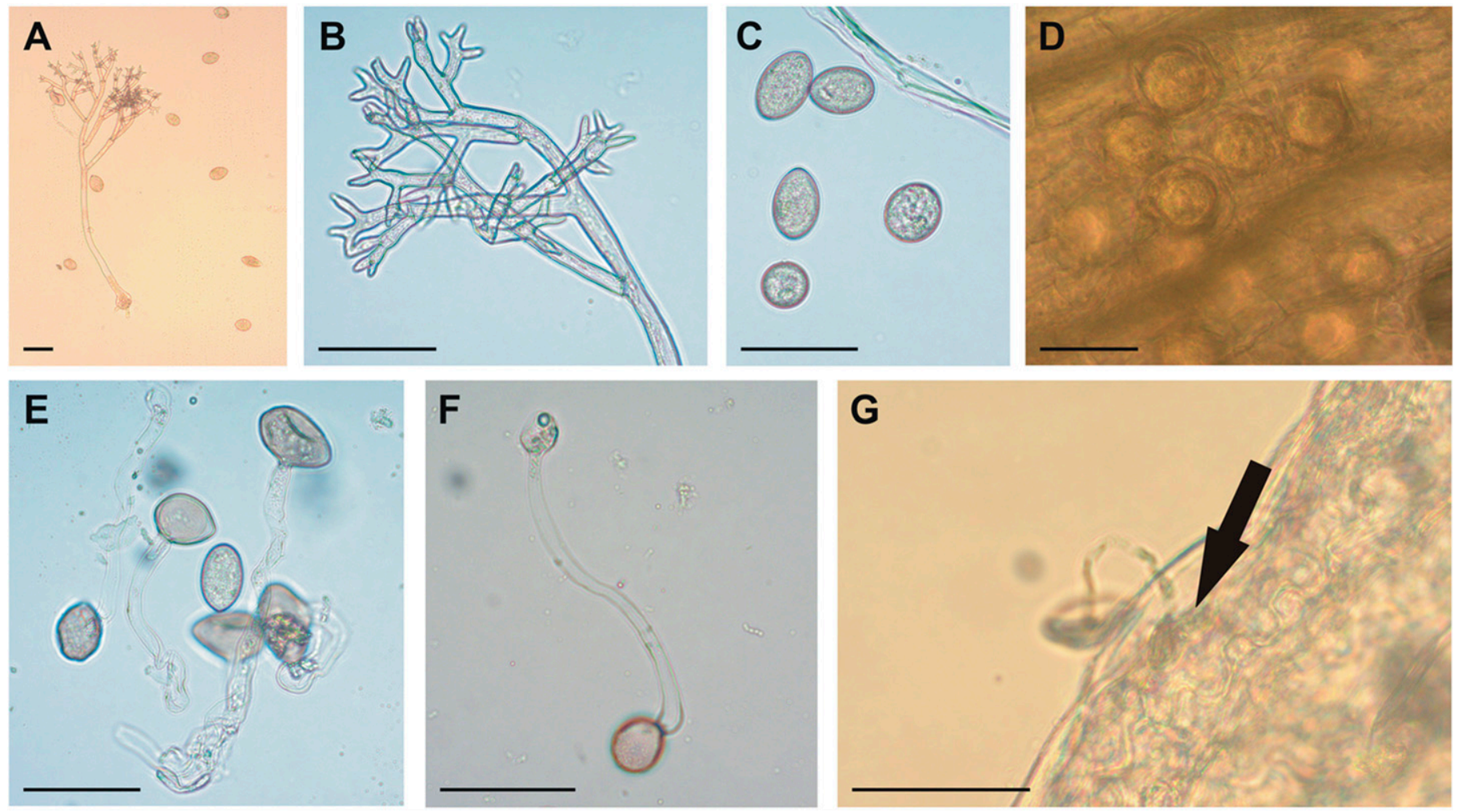

Fig. 2. Morphology of Peronospora radii. A and B, Hyaline conidiophores, which branched mainly dichotomously. C, Brownish, obovoidal to broadly ellipsoidal or globose apapillate conidia. D, Oospores. $\mathbf{E}$ and $\mathbf{F}$, Germination of conidia in a germ tube ending with appressoria. G, Germinated conidium with appressorium formed on a ligulate floret. The arrow indicates the appressorium. Scale bar $=50 \mu \mathrm{m}$. 
described by other authors (Constantinescu 1989; Koike et al. 2004; Šafránková and Müller 2007) but, nevertheless, they corresponded with the size of $P$. radii conidia from $T$. perforatum flowers (Ben-ze'ev et al. 1987). We observed only apapillate conidia on chamomile, whereas Israeli $P$. radii conidia with papillate apices were described as well, albeit less frequently on flowers than on leaves (Ben-ze'ev et al. 1987). $P$. radii conidia germination by a germ tube has been described for this species (Ben-ze'ev et al. 1987; Constantinescu 1989) but, in this work, appressoria formation was observed and described for the first time. Oospores were found in flowers (ligulate florets) and not in other parts of the tested chamomile plant (i.e., stem), which is in agreement with the description provided by Constantinescu (1989). On chrysanthemum plants, there are no current reports of oospore presence for $P$. radii (Ben-ze'ev et al. 1987; Koike et al. 2004; Šafránková and Müller 2007).

Molecular detection confirmed that floricolous downy mildew is caused by $P$. radii. Furthermore, results obtained from ITS and cox 2 gene analyses were congruent and confirmed a common monophyletic origin for floricolous downy mildews, as indicated previously (Thines and Kummer 2013; Voglmayr 2003). ITS was used to identify the pathogen from chamomile from Serbia and to analyze a cluster of $P$. radii strains but, due to the conserved nature of ITS in this group of organisms, no further differentiation in the $P$. radii clade was observed. Phylogenetic trees based on cox 2 sequences basically had a similar topology to those of ITS and were highly in agreement with those previously reported (Thines and Kummer 2013; Voglmayr 2003). The cox2 has lower sequence similarities than ITS, as confirmed by the phylogenetic analysis, which is consistent with the findings of Choi et al. (2015). The identity of both the ITS and the $\operatorname{cox} 2$ gene sequences of all $P$. radii tested herein should be the result of the uniform population of $P$. radii in the tested area. It remains unclear, however, whether the

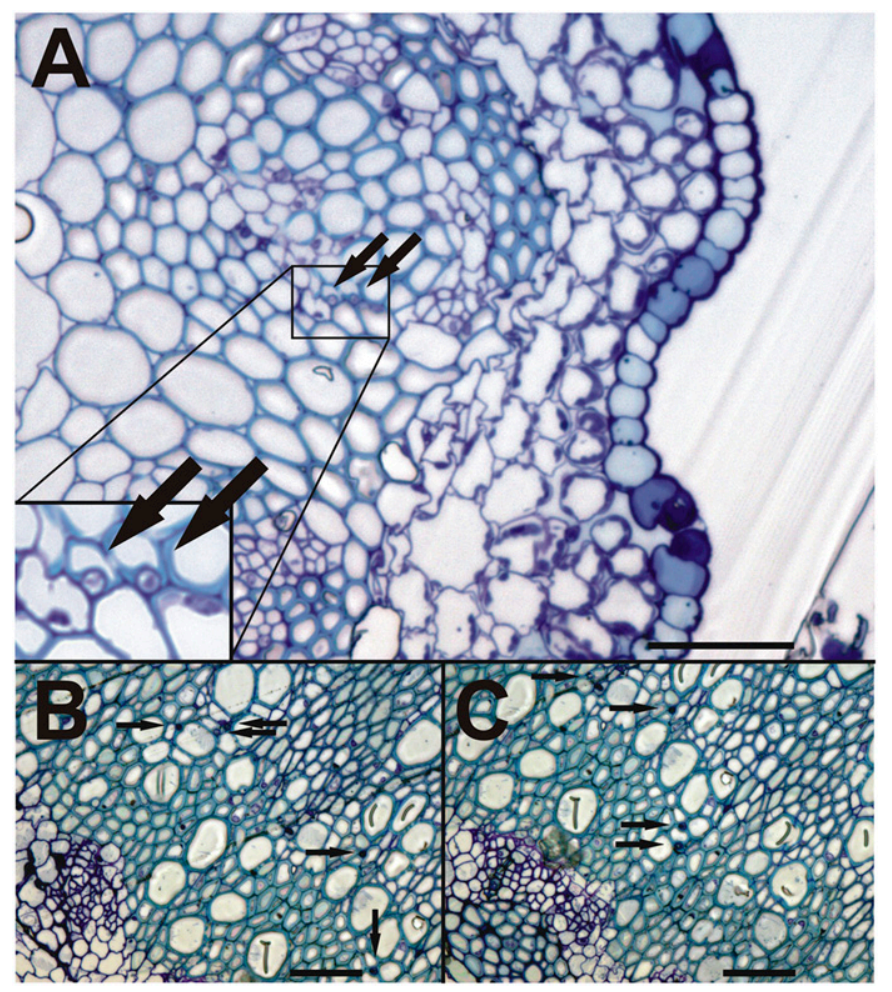

Fig. 3. Matricaria chamomilla stem systemically infected with Peronospora radii, observed by light microscopy. A, Transversal cut of an $M$. chamomilla stem section showing the tissue organization and localization of $P$. radii hyphae in the xylem (enlarged in a rectangle, not to scale). B and C, Transversal section of the localized area densely colonized by $P$. radii. Arrows indicate the presence of pathogen hyphae in the intracellular spaces of the xylem. Toluidine blue stains hyphae darker compared with xylem tissue. Scale bar $=50 \mu \mathrm{m}$. separation of the Serbian from the rest of $P$. radii strains in the cox 2 phylogenetic analyses was geographically correlated, because strains from different areas are needed for any conclusion to be drawn in this regard. Therefore, it would be interesting to investigate the phylogenetic relationships between chamomile and chrysanthemum $P$. radii strains, because the species is characterized as floricolous on chamomile and as nonfloricolous (foliicolous) on chrysanthemum. Moreover, some variability in its morphology regarding leaf and floret forms has been reported (Ben-ze'ev et al. 1987; Constantinescu 1989), and the sexual form of the pathogen is found only on chamomile. Therefore, it cannot be excluded that $P$. radii strains originating from chamomile and chrysanthemum can be separated into subclusters, especially if more informative markers are applied.

$P$. radii on chamomile has been known since the 19th century (De Bary 1863) and, to date, its systemic presence in the plant has not been demonstrated. Our molecular and ultrastructural analyses confirmed the floricolous pathogen $P$. radii in the stem below the flower and above the root neck, thus providing evidence that $P$. radii causes systemic infection in chamomile. LM examination with toluidine blue was useful in determining the position of the pathogen's hyphae in the vascular bundle due to its live nature and, therefore, dense staining in contrast to the xylem tracheid cells (Fig. 3 ). However, without the ability to stain $P$. radii hyphae and host plant tissue distinctively, the TEM analysis was essential for confirming that the observed structures were of the pathogens. In accordance with the results presented herein, the specific PCR, followed by sequence determination, confirmed that the pervasive structures belonged to $P$. radii. For $P$. violacea, another floricolous downy mildew of Knautia plants, systemic presence was assumed in the study of Horáková and Skalický (1989). Using LM, the authors revealed hyphae in the stems and rhizomes of Knautia plants infected with $P$. violacea. However, $P$. knautiae, a foliicolous pathogen of Knautia plants, may also be present in stems and rhizomes. Similarly, cases of the simultaneous incidence of two Peronosporaceae species, one floricolous and another foliicolous, on a single plant such as $P$. radii and Paraperonospora leptosperma on M. chamomilla have been reported (Constantinescu 1989). Therefore, confirmation of systemic infection by a floricolous
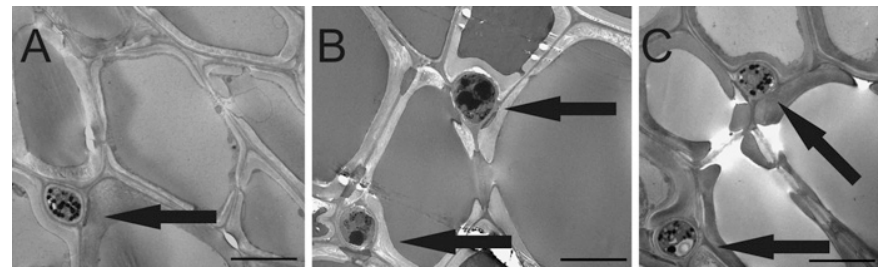

Fig. 4. Peronospora radii hyphae localized in the intercellular space of Matricaria chamomilla xylem, observed by transmission electron microscopy. $\mathbf{A}, \mathbf{B}$, and $\mathbf{C}$, Transversal section of the localized area of the xylem colonized by $P$. radii. Arrows indicate the presence of pathogen hyphae in the intracellular spaces of the xylem. Scale bar $=5 \mu \mathrm{m}$.

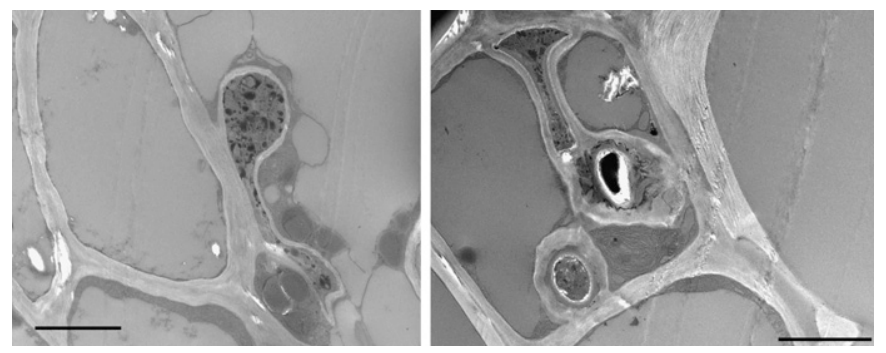

Fig. 5. Peronospora radii haustoria located in the xylem parenchyma cells of Matricaria chamomilla, observed by transmission electron microscopy. Transversal sections of the localized area of the xylem colonized by $P$. radii. Scale bar $=2 \mu \mathrm{m}$. 
pathogen has to be supported by proof that systemically present hyphae come from the floricolous pathogen, which is why reliable methods were used to determine the systemic presence of Peronospora radii in chamomile plants in this study.

The symptoms and earlier inflorescence which $P$. radii induced in chamomile indicate interference with flower development. The manipulation of flower organogenesis by floricolous downy mildews is suggested to be the result of the evolution of organspecific effector proteins and mechanisms restricting sporulation (Thines and Choi 2016). Later sporulation of $P$. radii occurred on malformed chamomile flowers, whereas no sporulation was found on the leaves or stems, which is in accordance with other results reported for chamomile (Buonaurio et al. 2004). Because flowers on systemically infected plants are sterile, such a modification may only serve to enhance pathogen reproduction (i.e., spore transmission by pollinators). A similar scenario has been shown to occur in the smut fungus Microbotryum violaceum (Shykoff and Kaltz 1998). Also, proliferative symptoms such as witches' brooms have already been described as being caused by graminicolous downy mildews, though they enhance spore transmission by wind and rain instead of pollinators (Thines and Kamoun 2010). In terms of phyllody, $P$. radii has raised host manipulation to an unprecedented level regarding filamentous plant pathogens, thus integrating the manipulation of flowering behavior and morphology. Therefore, elucidation of a probable role of effector proteins would be of outstanding interest.

Healthy chamomile seed that germinated in contaminated soil in a growth chamber developed disease symptoms and were molecularly confirmed as being infected, which led to the conclusion that the disease was soilborne. The source of inoculum could have been the oospores in ligulate florets that contaminated the soil in the experimental field. Oospores are known to be the main survival structures of other Peronospora spp. (i.e., P. viciae and $P$. manshurica) and are also known to be responsible for the systemic infection of host seedlings (Spencer 1981). The systemic presence of $P$. radii in overwintered young chamomile plants was confirmed in this study, suggesting infection of the seedlings in autumn. The possibility of the pathogen to overwinter in the form of oospores and to maintain infection potential and infect spring-sawn seedlings in early spring and in the next seasons should not be excluded. In chamomile crop production during summer breaks in cultivation, when there are no live host plants in the field, pathogen survival is probably ensured by oospores. Moreover, their persistence in soil, and their accumulation through chamomile regrowth over several successive years, may be the main avenue of primary infections.

$P$. radii conidia formed abundantly on malformed flowers and germinated with appressoria development only in the presence of host ligulate florets, which implies that the secondary flower infection of chamomile occurs from conidia. In support of this notion, oospores were observed in asymptomatic ligulate florets in flowers collected at the end of the growth season, where systemic infection was not confirmed. Earlier inflorescence of diseased plants, and the timing and abundance of sporulation which overlaps with healthy plant inflorescence, may ensure an abundance of conidia for infection at a time when healthy plants flower or in relation to the dispersal of spores via pollinating insects. The transmission of $P$. radii by pollinating insects may be supported by three facts: (i) the morphology of the conidiophore and its characteristic not to discharge conidia after desiccation, as suggested by Thines and Kummer (2013); (ii) sporulation limited to inflorescence; and (iii) secondary infections occurring from flower to flower. Along with soilborne infection, the impact of blossom infection increases during the growth season and may represent the way in which pathogens spread geographically.

The life cycle of an obligate parasite is always closely related to the life cycle of its host. In Serbia, chamomile is usually sown in autumn (September and October), during which time it germinates and forms a rosette, in order to overwinter. In the following spring, the plant forms its stem and elongates it and, at the end of April and in the first half of May, begins forming flowers, which are usually harvested in the second half of May. Because chamomile is an annual plant, and both volunteer (Matricaria chamomilla) and scentless ( $T$. perforatum) chamomile share the life cycle of
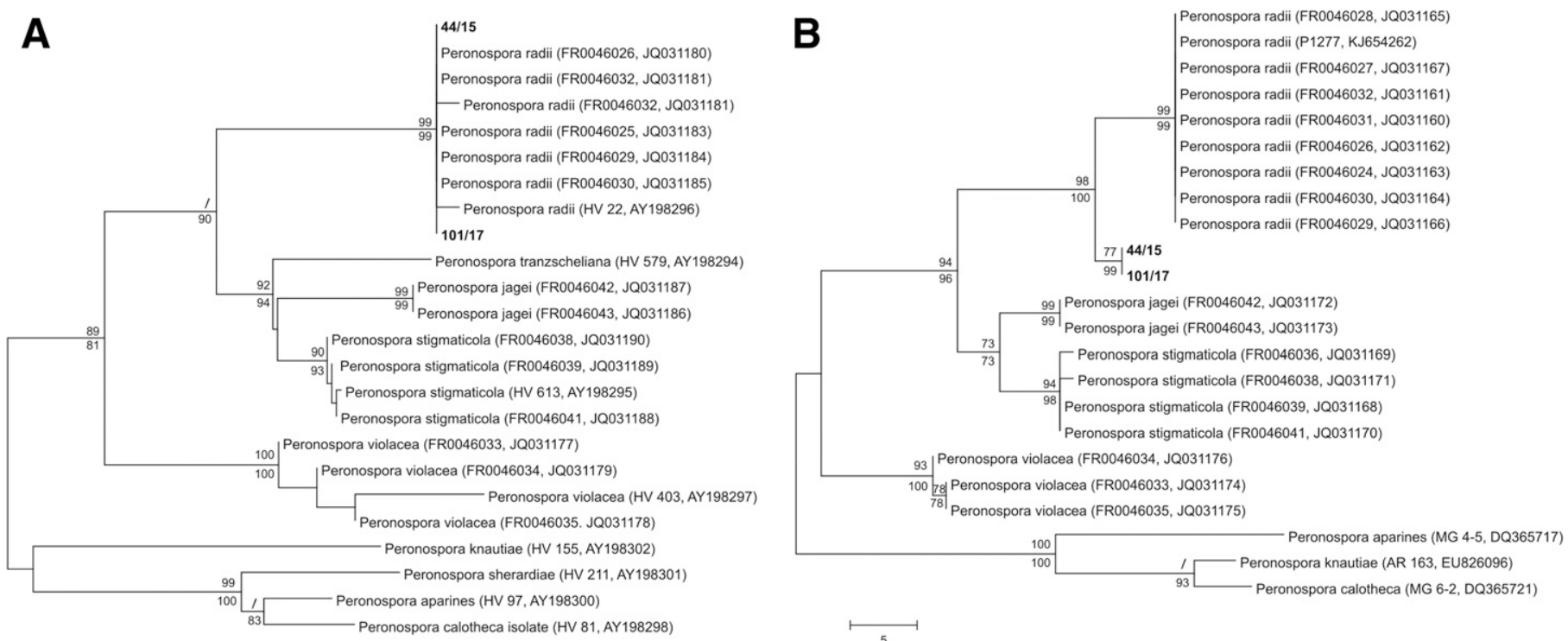

Fig. 6. Phylogenetic trees constructed by parsimony analysis of $\mathbf{A}$, internal transcribed spacer and $\mathbf{B}$, cox 2 sequences of Peronospora radii and other floricolous and closely related nonfloricolous Peronospora spp. Strains 44/15 and 101/17 (in bold) were obtained in this work, while other Peronospora spp. strains have been identified previously (Thines and Kummer 2013; Voglmayr 2003). Strain names and accession numbers are given in parentheses. Numbers on the branches are bootstrap values obtained for 1,000 replicates (only values above 70\% are shown). Bootstrap support values refer to maximum likelihood (top) and maximum parsimony (bottom). Values $<70$ are marked with "/" or are not marked when there was no value $>70$ in any of the analyses. For both analyses, 1 of the 10 mostparsimonious trees is shown. The tree is drawn to scale, with branch lengths calculated using the average pathway method, and they are in units of the number of changes over the whole sequence. The scale bar represents five nucleotide substitutions. 
cultivated chamomile, from July to the next seedtime (September), fields are usually empty, thus making it impossible for an obligate parasite to survive in the live host. With regard to culturing practices in chamomile production, and based on the results obtained herein (soilborne nature of the disease, systemic infection, latent infection of overwintering seedlings, earlier inflorescence and symptom expression, abundant conidial formation, secondary infections, and formation of oospores in symptomatic ligulate florets and in ligulate florets of asymptomatic not systemically infected plants), the proposed tentative life cycle of the floricolous $P$. radii on chamomile could be as follows (Fig. 7).

Primary infection occurs from oospores germinating in soil and infecting seedlings. The infected plant is taken over (figuratively "hijacked") and serves the purpose purely of pathogen reproduction and its spread (Fig. 7A). The pathogen overwinters in asymptomatic, systemically infected plants (Fig. 7B) and stays inconspicuous until inflorescence. Intercellular hyphae in the xylem follow stem growth toward inflorescence (Figs. 3 and 4), and the pathogen forms haustoria in the host cells (Fig. 5). Infected plants flower earlier than healthy ones (Fig. 7C), and the pathogen forms abundant conidiophores with conidia on ligulate florets (Figs. 1 and 7D). This coincides approximately with the beginning of the inflorescence of healthy plants. Profuse oospores are formed in some ligulate florets of infected plants (Figs. 2D and 7E), which eventually reach the soil (Fig. 7F). Secondary infections and geographical expansion occur through transmission by insects or wind or rain (Fig. 7G). On secondarily infected as well as in some primarily infected inflorescence, oospores are formed.

Some parts of the proposed life cycle still need experimental confirmation, such as the transmission of conidia by insects or wind or rain and the viability of the pathogen in the soil. Nonetheless, these results contribute to the knowledge of floricolous Peronospora spp. Gaining a suitable understanding of $P$. radii's life cycle will enable the implementation of proper disease control strategies (through adjusting cultural practice such as crop rotation and

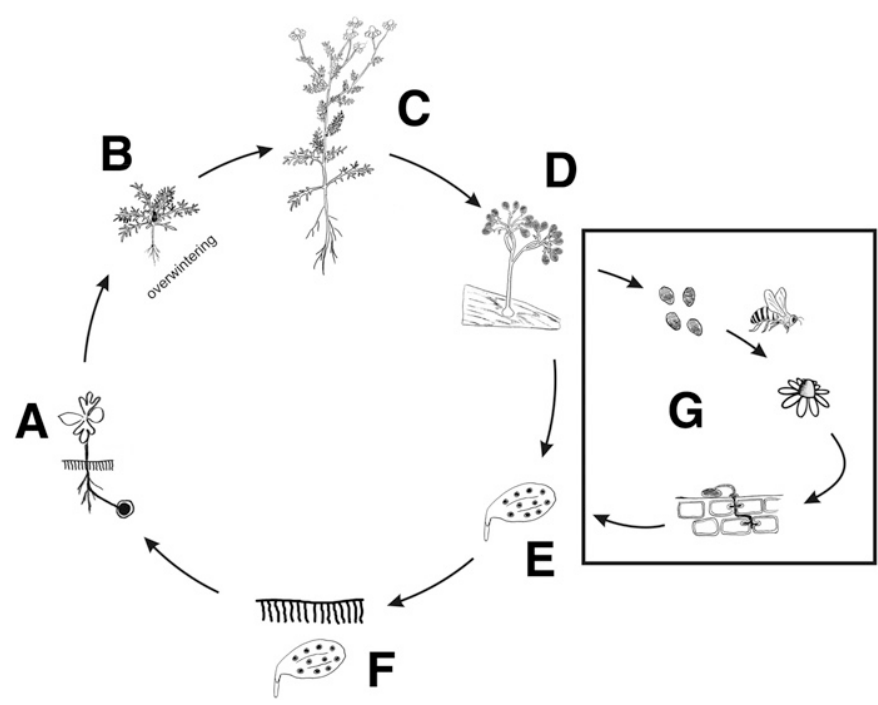

Fig. 7. Schematic representation of the proposed life cycle of Peronospora radii on chamomile. A, Infection arises from oospores germinating in soil and infecting a seedling. B, The pathogen overwinters in asymptomatic, systemically infected plants. C, Intercellular hyphae in the xylem follow stem growth, in order to reach inflorescence. The pathogen forms haustoria in host cells. Infected plants flower earlier then healthy ones. D, The pathogen forms abundant conidiophores, with conidia on ligulate florets of the infected plants. This coincides approximately with the inflorescence of healthy plants. E, Profuse oospores are formed in some infected plants' ligulate florets. F, Ligulate florets of the infected plants with oospores reach the soil. G, Secondary infections (in the rectangle) occur following insect transmission or spreading by wind or rain. tillage), especially because chemical treatments against diseases in medicinal plant production are highly undesirable.

\section{LITERATURE CITED}

Ben-ze'ev, I. S., Kenneth, R. G., and Bonde, M. R. 1987. Peronospora radii de Bary, a causal agent of downy mildew of Anthemideae: Complementary description and new hosts recorded in Israel. Phytoparasitica 15:51-67.

Bonants, P., Weerdt, M. H., van Gent-Pelzer, M., Lacourt, I., Cooke, D., and Duncan, J. 1997. Detection and identification of Phytophthora fragariae Hickman by the polymerase chain reaction. Eur. J. Plant Pathol. 103: 345-355.

Buonaurio, R., Polverari, A., and Cappelli, C. 2004. Peronospora radii De Bary, new parasite of common chamomile in Italy. Pages 93-96 in: Conf. Proc. Perspect. Prod. Use Med. Plants: Chamomile [Atti del convegno: Prospettive di produzione e di impiego delle piante officinali: la camomilla], San Sepolcro (AR), Pistrino (PG), Italia.

Choi, Y.-J., Beakes, G., Glockling, S., Kruse, J., Nam, B., Nigrelli, L., Ploch, S., Shin, H. D., Shivas, R. G., Telle, S., and Voglmayr, H. 2015. Towards a universal barcode of oomycetes-A comparison of the $\operatorname{cox} 1$ and $\operatorname{cox} 2$ loci. Mol. Ecol. Resour. 15:1275-1288.

Constantinescu, O. 1989. Peronospora complex on Compositae. Sydowia 41: 79-107.

Constantinescu, O. 1991. An Annotated List of Peronospora Names. Botanical Museum, Uppsala University, Uppsala, Sweden.

De Bary, A. 1863. Recherches sur le développement de quelques champignons parasites. Ann. Sci. Nat. Bot. 20:5-148.

Doyle, J. J., and Doyle, J. L. 1990. Isolation of plant DNA from fresh tissue. Focus 12:13-15.

Duduk, B., Paltrinieri, S., Lee, I.-M., and Bertaccini, A. 2013. Nested PCR and RFLP analysis based on the 16S rRNA gene. Pages 159-171 in: Phytoplasma, Methods in Molecular Biology. Methods in Molecular Biology, Vol. 938. M. Dickinson and J. Hodgetts, eds. Humana Press, Totowa, NJ

Hess, M., Barralis, G., Bleiholder, H., Buhr, L., Eggers, T., Hack, H., and Stauss, R. 1997. Use of the extended BBCH scale-General for the descriptions of the growth stages of mono; and dicotyledonous weed species. Weed Res. 37:433-441.

Horáková, J., and Skalický, V. 1989. Contribution to the ecology of Peronospora violacea Berk. Ceska Mykol. 43:13-29.

Hudspeth, D. S. S., Nadler, S. A., and Hudspeth, M. E. S. 2000. A COX2 molecular phylogeny of the Peronosporomycetes. Mycologia 92:674-684.

Koike, S. T., Fogle, D., Tjosvold, S. A., and King, A. I. 2004. Downy mildew caused by Peronospora radii on Marguerite daisy (Argyranthemum frutescens) in California. Plant Dis. 88:1163.

Kumar, S., Stecher, G., and Tamura, K. 2016. MEGA7: Molecular evolutionary genetics analysis version 7.0 for bigger datasets. Mol. Biol. Evol. $33: 1870-1874$

Šafránková, I., and Müller, J. 2007. The occurrence of Peronospora radii de Bary on Argyranthemum frutescens (L.) Schultz-Bip. in the Czech Republic. Acta Univ. Agric. Silvic. Mendel. Brun. 55:205-210.

Shykoff, J. A., and Kaltz, O. 1998. Phenotypic changes in host plants diseased by Microbotryum violaceum: Parasite manipulation, side effects, and tradeoffs. Int. J. Plant Sci. 159:236-243.

Silvar, C., Duncan, J. M., Cooke, D. E. L., Williams, N. A., Díaz, J., and Merino, F. 2005. Development of specific PCR primers for identification and detection of Phytophthora capsici Leon. Eur. J. Plant Pathol. 112:43-52.

Spencer, D. M. 1981. The Downy Mildews. Academic Press, London, New York.

Staden, R., Beal, K. F., and Bonfield, J. K. 2000. The Staden package. Methods Mol. Biol. 132:115-130.

Thines, M., and Choi, Y.-J. 2016. Evolution, diversity, and taxonomy of the Peronosporaceae, with focus on the genus Peronospora. Phytopathology 106:6-18.

Thines, M., and Kamoun, S. 2010. Oomycete-plant coevolution: Recent advances and future prospects. Curr. Opin. Plant Biol. 13:427-433.

Thines, M., and Kummer, V. 2013. Diversity and species boundaries in floricolous downy mildews. Mycol. Prog. 12:321-329.

Thompson, J. D., Gibson, T. J., Plewniak, F., Jeanmougin, F., and Higgins, D. G. 1997. The CLUSTAL_X Windows interface: Flexible strategies for multiple sequence alignment aided by quality analysis tools. Nucleic Acids Res. 25:4876-4882.

Voglmayr, H. 2003. Phylogenetic relationships of Peronospora and related genera based on nuclear ribosomal ITS sequences. Mycol. Res. 107: 1132-1142.

White, T., Bruns, T., Lee, S., and Taylor, W. 1990. Amplification and direct sequencing of fungal ribosomal RNA genes for phylogenetics. Pages 315-322 in: PCR Protocols: A Guide to Methods and Applications. Academic Press, Inc., New York, NY U.S.A. 